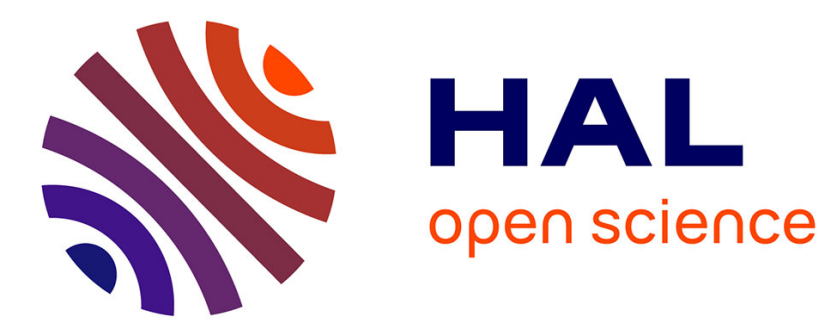

\title{
Diagnostic approach to sleep disordered-breathing among patients with grade III obesity
}

Elisa Perger, Judith Aron-Wisnewsky, Isabelle Arnulf, Jean-Michel Oppert, Stefania Redolfi

\section{- To cite this version:}

Elisa Perger, Judith Aron-Wisnewsky, Isabelle Arnulf, Jean-Michel Oppert, Stefania Redolfi. Diagnostic approach to sleep disordered-breathing among patients with grade III obesity. Sleep Medicine, 2021, 82, pp.18-22. 10.1016/j.sleep.2021.03.024 . hal-03270849

\section{HAL Id: hal-03270849 \\ https: / hal.sorbonne-universite.fr/hal-03270849}

Submitted on 25 Jun 2021

HAL is a multi-disciplinary open access archive for the deposit and dissemination of scientific research documents, whether they are published or not. The documents may come from teaching and research institutions in France or abroad, or from public or private research centers.
L'archive ouverte pluridisciplinaire HAL, est destinée au dépôt et à la diffusion de documents scientifiques de niveau recherche, publiés ou non, émanant des établissements d'enseignement et de recherche français ou étrangers, des laboratoires publics ou privés. 


\section{Diagnostic approach to sleep disordered-breathing among patients with grade III obesity}

Elisa Perger ${ }^{1,2,3}$ MD, Judith Aron-Wisnewsky ${ }^{4,5} \mathrm{MD}$, Isabelle Arnulf ${ }^{1} \mathrm{MD}$, Jean-Michel Oppert ${ }^{4} \mathrm{MD}$, Stefania Redolfi ${ }^{1,6} \mathrm{MD}, \mathrm{PhD}$.

${ }^{1}$ AP-HP, Groupe Hospitalier Universitaire APHP-Sorbonne Université, site Pitié-Salpêtrière, Service de Pathologies du Sommeil (Département R3S), F-75013 Paris, France; ${ }^{2}$ Istituto Auxologico Italiano IRCCS San Luca Hospital, Sleep Disorders Center \& Department of Cardiovascular, Neural and Metabolic Sciences, Milan, Italy; ${ }^{3}$ University of Milano-Bicocca, Milan, Italy; ${ }^{4}$ APHP, Groupe Hospitalier Pitié-Salpêtrière, Service de Nutrition, Sorbonne Université, Paris, France; ${ }^{5}$ Nutriomics, INSERM, Sorbonne Université, Paris, France; ${ }^{6}$ Sorbonne Université, INSERM, UMRS1158 Neurophysiologie respiratoire expérimentale et clinique, Paris, France

\section{Corresponding author:}

Elisa Perger, MD

AP-HP, Groupe Hospitalier Universitaire APHP-Sorbonne Université, site Pitié-Salpêtrière, Service de Pathologies du Sommeil (Département R3S), F-75013 Paris, France Email:

elisaperger@hotmail.com

This work was performed at the AP-HP, Groupe Hospitalier Universitaire APHP-Sorbonne Université, site Pitié-Salpêtrière, Service de Pathologies du Sommeil (Département R3S

Conflict of interest: No conflict to disclose

\section{All authors have seen and approved the manuscript}

Financial or non-financial disclosure: Nothing to declare

Tables: 2

Figures: 2

Manuscript : 2063 words

Abstract: 249

Brief summary: 90 


\section{ABSTRACT}

Sleep apnea test (SAT) is a cost-effective approach to evaluate subjects without associated comorbidities suspected for obstructive sleep apnea (OSA), a disorder particularly common in obese subjects. The association of obesity with awake hypercapnia (carbon dioxide arterial pressure, $\mathrm{PaCO}_{2}$ $\geq 45 \mathrm{mmHg}$ ) defines the obesity-hypoventilation syndrome (OHS), which in turn results in increased morbidity and mortality compared to simple OSA. Isolated hypoventilation during sleep in obese patients (obesity-related sleep hypoventilation, ORSH) is now considered as an early stage of OHS. The aim of this study was to assess the performance of SAT in diagnosing OSA and predicting the presence of ORHS among patients with grade III obesity without awake hypercapnia.

Methods: Over a 14-months period, patients with grade III obesity (body mass index $\geq 40 \mathrm{~kg} / \mathrm{m}^{2}$ ) presenting moderate-to-severe OSA (apnea-hypopnea index $[\mathrm{AHI}] \geq 15$ ) upon SAT and normal awake $\mathrm{PaCO}_{2}$ at arterial blood gas analysis, systematically underwent in-lab nocturnal polysomnography combined with transcutaneous carbon dioxide pressure $\left(\mathrm{PtcCO}_{2}\right)$ monitoring.

Results: Among 48 patients included in the study, 16 (33\%) presented an $\mathrm{AHI}<15$ upon polysomnography and 14 (29\%) had ORSH. The test revealed no difference in ORSH prevalence between patients with $\mathrm{AHI}<15$ or $\geq 15$ (31\% vs. $25 \%$ ). No SAT variables were independently associated with increased $\mathrm{PtCO}_{2}$.

Conclusions: This study shows that SAT overestimates OSA severity and ORSH affects one third of patients with grade III obesity without awake hypercapnia and with moderate-to-severe OSA at SAT, suggesting how polysomnography combined with $\mathrm{PtCO}_{2}$ monitoring is the most appropriate diagnostic approach for OSA and ORSH in this population.

\section{Keywords}

hypoventilation, OHS, OSA, obesity, polygraphy, polysomnography 


\section{Brief Summary:}

Among subject with grade III obesity (body mass index $\geq 40 \mathrm{~kg} / \mathrm{m} 2$ ) obstructive sleep apnea is highly prevalent and obesity hypoventilation syndrome is often underdiagnosed. Although home sleep apnea tests are frequently used to evaluate sleep disordered breathing, the pertinence of this test in subjects with grade III obesity has never been studied. For the first time we evaluated the performance of sleep apnea test compared to in-lab nocturnal polysomnography combined with transcutaneous carbon dioxide pressure monitoring in this population. Appropriate better diagnostic approaches might drive to better clinical intervention.

\section{Abbreviation list}

AASM: American Academy of Sleep Medicine

AHI: apnea-hypopnea index

BMI: body mass index

CSA: central sleep apnea

OHS: obesity hypoventilation syndrome

ORSH: obesity-related sleep hypoventilation

OSA: Obstructive sleep apnea

$\mathrm{PaCO}_{2}$ : carbon dioxide arterial pressure

PtcCO2: transcutaneous carbon dioxide pressure

SAT: sleep apnea test

EEG: electroencephalogram 


\section{INTRODUCTION}

Obstructive sleep apnea (OSA) is usually diagnosed through portable sleep apnea test (SAT) in patients without associated comorbidities [1]. OSA is common in patients with obesity and its prevalence rises with increasing body mass index (BMI). In $20 \%$ of patients with grade I obesity $\left(B M I \geq 30 \mathrm{~kg} / \mathrm{m}^{2}\right.$ ) and $30 \%$ of those with grade III obesity (BMI $\geq 40 \mathrm{~kg} / \mathrm{m}^{2}$ ) seen in sleep clinics, OSA is associated with awake hypercapnia (carbon dioxide arterial pressure, $\mathrm{PaCO}_{2} \geq 45 \mathrm{mmHg}$ ) without other known causes of hypoventilation: this condition defines the obesity-hypoventilation syndrome (OHS) [2, 3]. Compared to isolated OSA, OHS results in increased morbidity and mortality rates $[3,4]$. However, OHS remains largely undiagnosed and untreated until patients require intensive care unit admission for acute decompensation [3, 4]. Therefore, a timely identification and management of the earlier OHS stages might improve patients' prognosis. It is believed that isolated sleep hypoventilation (defined as a transcutaneous carbon dioxide pressure, $\mathrm{PtcCO}_{2}>55 \mathrm{mmHg}$ or $>50 \mathrm{mmHg}$ if $\mathrm{PtcCO}_{2}$ increases by more than $10 \mathrm{mmHg}$ for more than 10 minutes of sleep compared to awake supine value) without awake hypercapnia precedes OHS, similarly to what is observed in neuromuscular and chest wall diseases $[5,6]$. This condition is called obesity-related sleep hypoventilation (ORSH) and it is now considered as an early stage of hypoventilation in patients with obesity[7, 8]. Recent evidence has shown that $19 \%$ of patients with grade III obesity undergoing polysomnography with $\mathrm{PtcCO}_{2}$ monitoring for suspected sleep-disordered breathing present ORSH [9], thus supporting the effectiveness of such combined diagnostic approach during sleep to correctly identify sleep-disordered breathing in this population.

We aimed at evaluating the performance of SAT in the diagnosis of sleep-disordered breathing in this population. Thus, we performed polysomnography combined with $\mathrm{PtcCO}_{2}$ monitoring among patients with grade III obesity, who present moderate-to-severe OSA (apnea-hypopnea index, AHI $\geq 15$ /hour) upon SAT and without awake hypercapnia. 


\section{METHODS}

\section{Patients}

Patients with grade III obesity hospitalized in the nutrition department of our university hospital for a first assessment of obesity-related comorbidities in stable condition were evaluated for study inclusion. During the hospitalization all patients routinely undergo SAT and arterial blood gas analysis. Subsequently, patients presenting moderate-to severe OSA (AHI $\geq 15$ ) upon SAT are referred to the sleep clinic of the same hospital for in-lab PSG evaluation. We selected over a 14months period patients with a $\mathrm{BMI} \geq 40 \mathrm{~kg} / \mathrm{m}^{2}$ and normal awake $\mathrm{PaCO}_{2}$ to undergo in-lab polysomnography combined with $\mathrm{PtcCO}_{2}$ monitoring. The subjects presenting chronic obstructive pulmonary disease, severe asthma, ischemic cardiomyopathy, severe neurological diseases such as multiple sclerosis, advanced Parkinson disease and recent (less than 3 months) stroke or unstable respiratory, cardiac diseases or those who had been already treated for OSA, were not included in the study. Further exclusion criteria were predominant central or mixed sleep apnea $(>50 \%$ of central or mixed respiratory events at the in-lab polysomnography). The patients were grouped according to the presence or absence of sleep hypoventilation in line with the definition of the American Academy of Sleep Medicine (AASM) scoring manual [1]: $\mathrm{PtcCO}_{2}>55 \mathrm{mmHg}$ or $>50 \mathrm{mmHg}$ if $\mathrm{PtcCO}_{2}$ increases by more than $10 \mathrm{mmHg}$ for more than 10 minutes of sleep compared to awake supine value. The population was then divided into patients with moderate-to-severe OSA (apnea-hypopnea index, AHI $\geq 15)$ and patients with mild or no OSA $(\mathrm{AHI}<15)$ on the basis of polysomnography results. The cutoff of 15 events/hour was chosen for AHI, because this value is used to decide whether to treat or not OSA.

Demographic data, namely age, sex, weight and height were collected by technicians prior to the sleep study. Daytime sleepiness was assessed using the Epworth Sleepiness Scale score and defined as abnormal if $>10[10]$. The study is conformed to the standards set by the Declaration of Helsinki and received ethical clearance from the appropriate authority. All patients signed informed consent 
for the collection of their routine care clinical interviews and sleep tests to be entered in a database and used for research purposes.

\section{Sleep studies}

The SAT was carried out in the nutrition clinic using a Level 3 respiratory polygraphy (Cidelec, SteGemmes-sur-Loire, France). SAT were scored automatically first and then were revised manually according with AASM scoring criteria[1]. Oxygen desaturation index (ODI) was evaluated at 3\% threshold for both SAT and PSG. The polysomnography (Grael HD PSG/EEG system, Compumedics, Sydney, Australia) combined with $\mathrm{PtcCO}_{2}$ monitoring (TOSCA/CombiM, Radiometer, Basel, Switzerland) was performed in the sleep clinic and included: 3-lead (Fp1/A2, C3/A2, O1/A2) electroencephalogram (EEG), right and left electrooculograms, electromyogram of the levator menti muscle for sleep stage assessment; right and left tibialis anterior electromyogram to check periodic leg movement. Both polysomnography and SAT recordings included nasal pressure and oral thermistor for oro-nasal flow assessment, thoracic and abdominal respiratory inductance plethysmography belts for the evaluation of respiratory efforts, pulse-oximetry, and 1-lead electrocardiogram. Sleep stages[11], arousals[12], periodic leg movements and respiratory events[13] were scored at the polysomnography by visual inspection using current AASM scoring rules[1].

\section{Statistical analysis}

The data are presented as numbers and percentages, mean \pm standard deviation, or median [interquartile range] as appropriate, after testing for normality distribution with Shapiro-Wilk's test. Continuous variables were compared using a two-tailed unpaired t-test or the Mann-Whitney test for asymmetrically distributed data. Fisher's exact test was used to compare categorical variables. We performed a multivariate logistic regression to evaluate SAT variable associated with sleep hypoventilation (presence or not of ORSH) including SAT mean SpO2, SAT min SpO2, SAT AHI and SAT ODI as dependent variables. A p value of $<0.05$ was considered as statistically significant. 
Statistical analyses were performed using SPSS 19.00 (IBM, Armonk, NY) and Graph Pad Prism 6.0 (McKiev Software, Boston, MA).

\section{RESULTS}

Among the 51 subjects addressed in our sleep clinic, 3 had central sleep apnea and were thus excluded. The characteristics of the 48 patients included in the analysis are presented in Tables 1 . The final diagnosis of sleep-disordered breathing, according to polysomnography combined with PtcCO2 monitoring are summarized in Figure 1. Surprisingly, 16 patients (34\%) presented an AHI $<15$ upon polysomnography (despite having an AHI $\geq 15$ upon SAT), leading to false positive OSA diagnosis (Figure 2).

The mean time between SAT and PSG execution was $2.7 \pm 1.9$ months for those with an AHI $<15$ and $3.1 \pm 2.8$ months $(\mathrm{p}=0.58)$. During this time-frame there was no changes in general clinical conditions or medication intake. Weight did not change significantly between the groups, being 0.9 $\pm 9.1 \mathrm{Kg}$ in the group with an $\mathrm{AHI}>15$ and $1.4 \pm 2.4 \mathrm{Kg}$ in the group with an $\mathrm{AHI}<15(\mathrm{p}=0.83)$.

Sleep hypoventilation was present in $29 \%$ of patients without significant difference between patients with $\mathrm{AHI}<15$ and those with $\mathrm{AHI} \geq 15(25 \%$ vs. $31 \%, \mathrm{p}=0.65)$ (Figure 1$)$.

Tables 1 and 2 report the comparisons between subjects with an AHI $<15$ and $\geq 15$ upon polysomnography and between subject with and without sleep hypoventilation. Subjects with an AHI $\geq 15$ presented more frequently a diagnosis of depression and had lower percentage of hypopnea at the SAT than those with an AHI $<15$. The SAT SpO2 nadir was lower in subjects presenting sleep hypoventilation. Regarding PSG characteristics, N3 sleep was lower in subjects with sleep hypoventilation than those without (Table 2). AHI and oxygen desaturation index did not differ between subject with or without sleep hypoventilation. Patients presenting sleep hypoventilation had lower mean $\mathrm{SpO} 2$ during REM sleep, lower nadir $\mathrm{SpO} 2$ and spent more time with $\mathrm{SpO} 2<90 \%$. Among SAT variables, no independent predictors of sleep hypoventilation emerged. 


\section{DISCUSSION}

This is the first study showing an overestimation of AHI using SAT in comparison to polysomnography in patients with grade III obesity. We also highlighted how one third of them was incorrectly diagnosed as moderate-to severe OSA by SAT. Moreover, our data confirmed that the prevalence of sleep hypoventilation was high (29\%) in grade III obesity patients without OHS and did not differ between those with and without moderate-to-severe OSA upon polysomnography. These results support the poor adequacy of SAT and corroborate the necessity of polysomnography combined with $\mathrm{PtcCO}_{2}$ monitoring to appropriately diagnose sleep-disordered breathing in such population [6].

SAT expedites the detection of OSA and reduces the costs associated with in-lab polysomnography in adult patients with a high pretest probability of moderate-to-severe OSA. [14-16]. Although type III portable monitoring have previously been proposed for diagnosis of sleep apnea also in the hospital settings among different populations[17-19], to our knowledge no validation with PSG have been performed. One study evaluated the night-to-night variability of SDB diagnosis with portable type III and type IV monitoring [20], but the comparison with PSG results was not performed. Unlike polysomnography, SAT cannot measure the duration of sleep and the number of arousals, which potentially underestimates $\mathrm{AHI}$ in case of shorter total sleep time than total recording time or in case of hypopneas associated with arousals and no oxygen desaturation. Surprisingly, our results show an opposite trend, indicating an overestimation of AHI by SAT compared to polysomnography and leading to over-diagnosis of OSA. Mild hypoxemia is common in obese patients without cardiopulmonary disease, as oxygen levels drops with increasing BMI, independently of hypoventilation [21]. In fact, obesity can cause hypoxemia by decreasing lung volumes to the point of closing lung units during normal breathing, which promotes the passage of deoxygenated blood from the right to the left side of the heart without participation in gas exchange in the pulmonary capillaries (intrapulmonary shunt). This phenomenon is amplified in the supine position. Mild 
hypoxemia corresponds to the lowest portion of the oxygen-hemoglobin dissociation curve, so that, compared to the flat upper part of the curve at higher levels of oxygenation, the same decrease in arterial oxygenation is associated with a greater reduction in the percentage of oxygenated hemoglobin. In these conditions, small changes in tidal volume can result in fluctuations of hemoglobin saturation, even in awake lying obese patients. It is therefore possible that in these subjects, physiological fluctuations in tidal volume, occurring while awake in supine position, might lead to oxygen desaturation misinterpreted as hypopneas in simple SAT, explaining the trend toward AHI overestimation compared to the values measured during polysomnography, which are restricted to sleep time. To confirm this, the percentage of hypopnea at SAT was higher in subjects with AHI $<15$ at the polysomnography. The overestimation of OSA severity might bring to erroneous therapy prescription, with consequent difficult tolerance, inadequate compliance and increased healthcare costs.

Recently, Sivam et al. reported the presence of isolated sleep hypoventilation in a group of 94 subjects with grade III obesity patients referred to the sleep clinic for assessing sleep-disordered breathing [9]. Compared to the population evaluated by Sivam et al., we found higher prevalence of isolated sleep hypoventilation (19\% vs. $29 \%$, respectively), even though our patients had a less severe obesity (mean BMI: 48 vs. $52 \mathrm{~kg} / \mathrm{m}^{2}$ ) and a milder OSA (mean AHI: 33 vs 65), probably related to our selection criterion based on a previous SAT showing an AHI $>15$. We demonstrated that the prevalence of sleep hypoventilation was comparable in patients with and without moderate-to severe OSA at polysomnography, suggesting the independence of OSA and sleep hypoventilation in this specific obese population.

Given the selection of patients with grade III obesity in our study population for study design, we cannot generalize our findings to all potential patient populations with obesity. Further studies will need to be performed to confirm our results in different populations with obesity. Moreover, 
although we also demonstrated the necessity of EEG to correctly detect respiratory events only during sleep, the accuracy of a SAT combined with $\mathrm{PtcCO}_{2}$ monitoring need to be also evaluated.

Our findings reveal that SAT is not appropriate to diagnose sleep-disordered breathing in patients with morbid obesity without awake hypercapnia, as it overestimates OSA severity in about one third of the cases and fails to recognize isolated sleep hypoventilation in another third, regardless of OSA severity. These results are clinically relevant because the early identification of sleep hypoventilation in morbid obese patients may allow timely initiation of multimodal treatment, thus potentially preventing advanced OHS decompensation[6]. Morbid obesity, even without awake hypercapnia, should be considered as a comorbidity indicating the inappropriate use of SAT in the diagnosis of sleep-disordered breathing. Since obesity is a growing worldwide problem implying elevated healthcare costs, a correct diagnostic approach for sleep-disordered breathing appears to be a valuable tool to prevent inadequate and/or delayed treatment interventions.

Figure 1: Distribution of sleep-disordered breathing. BMI: body mass index; AHI: apnea-hypopnea index; SAT: sleep apnea test; $\mathrm{PaCO}_{2}$ : carbon dioxide arterial pressure; $\mathrm{PtcCO}_{2}$ : transcutaneous carbon dioxide pressure; CSA: central sleep apnea.

Figure 2: Comparison of apnea-hypopnea index between home sleep apnea test (HSAT) and in-lab polysomnography (PSG) 


\section{REFERENCE LIST}

[1] Kapur VK, Auckley DH, Chowdhuri S, Kuhlmann DC, Mehra R, Ramar K, et al. Clinical Practice Guideline for Diagnostic Testing for Adult Obstructive Sleep Apnea: An American Academy of Sleep Medicine Clinical Practice Guideline. J Clin Sleep Med. 2017;13:479-504.

[2] Macavei VM, Spurling KJ, Loft J, Makker HK. Diagnostic predictors of obesity-hypoventilation syndrome in patients suspected of having sleep disordered breathing. J Clin Sleep Med. 2013;9:879-84.

[3] Mokhlesi B. Obesity hypoventilation syndrome: a state-of-the-art review. Respir Care. 2010;55:1347-62; discussion 63-5.

[4] Nowbar S, Burkart KM, Gonzales R, Fedorowicz A, Gozansky WS, Gaudio JC, et al. Obesity-associated hypoventilation in hospitalized patients: prevalence, effects, and outcome. Am J Med. 2004;116:1-7.

[5] Piper AJ, Grunstein RR. Obesity hypoventilation syndrome: mechanisms and management. Am J Respir Crit Care Med. 2011;183:292-8.

[6] Böing S, Randerath WJ. Chronic hypoventilation syndromes and sleep-related hypoventilation. J Thorac Dis. 2015;7:1273-85.

[7] Randerath W, Verbraecken J, Andreas S, Arzt M, Bloch KE, Brack T, et al. Definition, discrimination, diagnosis and treatment of central breathing disturbances during sleep. Eur Respir J. 2017;49.

[8] Randerath WJ, BaHammam AS. Overlooking Obesity Hypoventilation Syndrome: The Need for Obesity Hypoventilation Syndrome Staging and Risk Stratification. Annals of the American Thoracic Society. 2020;17:1211-2.

[9] Sivam S, Yee B, Wong K, Wang D, Grunstein R, Piper A. Obesity Hypoventilation Syndrome: Early Detection of Nocturnal-Only Hypercapnia in an Obese Population. J Clin Sleep Med. 2018;14:1477-84.

[10] Johns MW. Sleepiness in different situations measured by the Epworth Sleepiness Scale. Sleep. 1994;17:703-10.

[11] Rechtschaffen A, Kales A. A Manual of Standardized Terminology, Techniques and Scoring System for Sleep Stages of Human Subjects1968.

[12] EEG arousals: scoring rules and examples: a preliminary report from the Sleep Disorders Atlas Task Force of the American Sleep Disorders Association. Sleep. 1992;15:173-84.

[13] Medicine AAoS. International classification of sleep disorders. 3rd ed: American Academy of Sleep Medicine; 2014.

[14] El Shayeb M, Topfer LA, Stafinski T, Pawluk L, Menon D. Diagnostic accuracy of level 3 portable sleep tests versus level 1 polysomnography for sleep-disordered breathing: a systematic review and meta-analysis. Cmaj. 2014;186:E25-51.

[15] Garg N, Rolle AJ, Lee TA, Prasad B. Home-based diagnosis of obstructive sleep apnea in an urban population. J Clin Sleep Med. 2014;10:879-85.

[16] Aurora RN, Swartz R, Punjabi NM. Misclassification of OSA severity with automated scoring of home sleep recordings. Chest. 2015;147:719-27.

[17] Perger E, Soranna D, Pengo M, Meriggi P, Lombardi C, Parati G. Sleep-disordered Breathing among Hospitalized Patients with COVID-19. Am J Respir Crit Care Med. 2021;203:239-41.

[18] Khayat RN, Jarjoura D, Patt B, Yamokoski T, Abraham WT. In-hospital testing for sleep-disordered breathing in hospitalized patients with decompensated heart failure: report of prevalence and patient characteristics. J Card Fail. 2009;15:739-46.

[19] Goring K, Collop N. Sleep disordered breathing in hospitalized patients. Journal of clinical sleep medicine : JCSM : official publication of the American Academy of Sleep Medicine. 2008;4:105-10.

[20] Fredheim JM, Røislien J, Hjelmesæth J. Validation of a Portable Monitor for the Diagnosis of Obstructive Sleep Apnea in Morbidly Obese Patients. Journal of Clinical Sleep Medicine. 2014;10:751-7.

[21] Littleton SW, Tulaimat A. The effects of obesity on lung volumes and oxygenation. Respir Med. 2017;124:15-20. 
Table 1. Characteristics of patients with an apnea-hypopnea index (AHI) $<15$ or $\geq 15$ at polysomnography, and with or without sleep hypoventilation.

\begin{tabular}{|c|c|c|c|c|c|}
\hline & $\begin{array}{l}\text { All patients } \\
\qquad \mathbf{n}=48\end{array}$ & $\begin{array}{c}\mathrm{AHI}<15 \\
n=16\end{array}$ & $\begin{array}{c}A H I \geq 15 \\
n=32\end{array}$ & $\begin{array}{c}\text { Without sleep } \\
\text { hypoventilation } \\
\mathbf{n}=\mathbf{3 4}\end{array}$ & $\begin{array}{c}\text { With sleep } \\
\text { hypoventilation } \\
n=14\end{array}$ \\
\hline Age, years & $47 \pm 16$ & $48 \pm 15$ & $46 \pm 14$ & $46 \pm 16$ & $48 \pm 12$ \\
\hline Male & $20(42)$ & $5(31)$ & $15(47)$ & $14(41)$ & $6(43)$ \\
\hline Weight, kg & $134[45]$ & $148[47]$ & $134[48]$ & 132 [39] & $147[40]$ \\
\hline Height, $\mathrm{cm}$ & $167[18]$ & $166[20]$ & $168[16]$ & $166[18]$ & $171[16]$ \\
\hline Body mass index, $\mathrm{kg} / \mathrm{m}^{2}$ & 48 [9] & $48[12]$ & 49 [9] & $44[13]$ & $51[5]$ \\
\hline Body surface area, $\mathrm{m}^{2}$ & $2.43 \pm 0.46$ & $2.39 \pm 0.37$ & $2.45 \pm 0.32$ & $2.40 \pm 0.37$ & $2.50 \pm 0.24$ \\
\hline \multicolumn{6}{|l|}{ Comorbidities, N (\%) } \\
\hline Hypertension & $25(52)$ & $8(50)$ & $17(53)$ & $18(53)$ & $7(50)$ \\
\hline Diabetes & $21(44)$ & $7(44)$ & $14(44)$ & $13(38)$ & $8(57)$ \\
\hline Dyslipidemia & $17(35)$ & $4(25)$ & $13(41)$ & $12(35)$ & $5(36)$ \\
\hline Heart failure & $2(4)$ & 0 & $2(6)$ & $2(6)$ & 0 \\
\hline Depression & $13(27)$ & $1(6)$ & $12(38) *$ & $9(26)$ & $4(29)$ \\
\hline \multicolumn{6}{|c|}{ Severity of sleepiness at the Epworth sleepiness score } \\
\hline Score (range $0-24$ ) & $8 \pm 8$ & $9 \pm 6$ & $8 \pm 6$ & $8 \pm 7$ & $8 \pm 5$ \\
\hline Score $>10$ & $14(29)$ & $6(38)$ & $8(25)$ & $9(26)$ & $5(36)$ \\
\hline \multicolumn{6}{|l|}{ Arterial blood gas } \\
\hline $\mathrm{pH}$ & $7.42 \pm 0.02$ & $7.42 \pm 0.02$ & $7.42 \pm 0.02$ & $7.43 \pm 0.03$ & $7.42 \pm 0.01$ \\
\hline $\mathrm{PaO}_{2}, \mathrm{mmHg}$ & $83.2[17.3]$ & $82[23]$ & $86[17]$ & $86.9[10.6]$ & 74.5 [19.4]\# \\
\hline $\mathrm{PaCO}_{2}, \mathrm{mmHg}$ & $39.0 \pm 5.3$ & $38.5 \pm 3.7$ & $39.3 \pm 3.4$ & $37.9 \pm 3.1$ & $41.7 \pm 2.9 \#$ \\
\hline Bicarbonate, $\mathrm{mmol} / \mathrm{l}$ & $24.8 \pm 2.2$ & $24.3 \pm 2.1$ & $25.0 \pm 1.5$ & $24.3 \pm 1.4$ & $25.9 \pm 1.9 \#$ \\
\hline \multicolumn{6}{|l|}{ Sleep apnea test } \\
\hline Apnea-hypopnea index & $44 \pm 28$ & $27 \pm 9$ & $52 \pm 24^{*}$ & $42 \pm 23$ & $49 \pm 26$ \\
\hline Oxygen desaturation index & $59 \pm 37$ & $44 \pm 19$ & $64 \pm 24^{*}$ & $55 \pm 23$ & $62 \pm 28$ \\
\hline Mean $\mathrm{SpO}_{2}, \%$ & $91[20]$ & $92[9]$ & $91[20]$ & $91[20]$ & $91[9]$ \\
\hline $\mathrm{SpO}_{2}$ Nadir, $\%$ & 75 [37] & $78[30]$ & $72[32]$ & $77[37]$ & $65[26] \#$ \\
\hline Time with $\mathrm{SpO}_{2}<90 \%, \%$ & $20[84]$ & 10 [89] & 25 [94] & $19[86]$ & $25[94]$ \\
\hline Hypopneas, \% of AHI & 87 [89] & $95[35]$ & $85[89]^{*}$ & 86 [89] & $96[35]$ \\
\hline
\end{tabular}

Data are expressed as $\mathrm{n}(\%)$, mean \pm standard deviation or as median [interquartile range].

Definition of abbreviations: $\mathrm{AHI}=$ apnea-hypopnea index; $\mathrm{PaO}_{2}=$ arterial oxygen pressure; $\mathrm{PaCO}_{2}=$ arterial carbon dioxide pressure; $\mathrm{SpO}_{2}=$ pulsed oxygen saturation.

$*=\mathrm{p}<0.05$ compared to subjects with AHI $<15$ at polysomnography; $\#=\mathrm{p}<0.05$ compared to subjects without sleep hypoventilation. 
Table 2. Polysomnographic characteristics in patients with an apnea-hypopnea index (AHI) $<$ 15 or $\geq 15$ at the polysomnography, and with and without sleep hypoventilation

\begin{tabular}{|c|c|c|c|c|c|}
\hline & $\begin{array}{l}\text { All patients } \\
\qquad n=48\end{array}$ & $\begin{array}{c}\text { AHI }<15 \\
n=16\end{array}$ & $\begin{array}{c}\mathrm{AHI} \geq 15 \\
\mathrm{n}=32\end{array}$ & $\begin{array}{c}\text { Without sleep } \\
\text { hypoventilation } \\
\mathbf{n}=\mathbf{3 4}\end{array}$ & $\begin{array}{c}\text { With sleep } \\
\text { hypoventilation } \\
\mathbf{n}=14\end{array}$ \\
\hline Total sleep time, min & $392 \pm 111$ & $370 \pm 116$ & $404 \pm 106$ & $405 \pm 112$ & $365 \pm 102$ \\
\hline Sleep efficiency, $\%$ & $81[15]$ & $79[28]$ & $81[13]$ & $78[15]$ & 74 [29] \\
\hline N1- N2 sleep, $\%$ & $65 \pm 11$ & $60 \pm 10$ & $69 \pm 10^{*}$ & $64 \pm 11$ & $69 \pm 9$ \\
\hline N3 sleep, $\%$ & $19 \pm 10$ & $24 \pm 9$ & $16 \pm 10^{*}$ & $21 \pm 10$ & $14 \pm 10 \#$ \\
\hline REM sleep, $\%$ & $15 \pm 5$ & $16 \pm 5$ & $15 \pm 6$ & $15 \pm 5$ & $17 \pm 5$ \\
\hline Arousal index, $/ \mathrm{h}$ & $23[23]$ & $17[9]$ & $27[30]^{*}$ & 19 [15] & $21[25]$ \\
\hline Apnea hypopnea index & $33 \pm 28$ & $6 \pm 3$ & $48 \pm 26^{*}$ & $32 \pm 29$ & $35 \pm 30$ \\
\hline Oxygen desaturation index & $44 \pm 34$ & $16 \pm 13$ & $61 \pm 34^{*}$ & $46 \pm 34$ & $45 \pm 41$ \\
\hline Mean REM SpO 2 & $90[6]$ & $91[5]$ & 89 [7] & $91[6]$ & 85 [13]\# \\
\hline Mean N1-3 $\mathrm{SpO}_{2}$ & $92[3]$ & $93[3]$ & $92[3]$ & $92[3]$ & $92[6]$ \\
\hline $\mathrm{SpO}_{2}$ Nadir & 73 [19] & 79 [12] & $69[19]^{*}$ & $75 \pm 10$ & $66 \pm 11 \#$ \\
\hline Time with $\mathrm{SpO}_{2}<90 \%, \%$ TST & $17[37]$ & $9[23]$ & $26[41]$ & $11[32]$ & $35[69] \#$ \\
\hline Time with $\mathrm{PtcCO}_{2}>50 \mathrm{mmHg}$, min & $0[56]$ & $0[37]$ & $2[64]$ & $0[4]$ & 68 [118]\# \\
\hline Time with $\mathrm{PtcCO}_{2}>55 \mathrm{mmHg}$, min & 0 [7] & $0[7]$ & $0[8]$ & $0[1]$ & $16[58] \#$ \\
\hline
\end{tabular}

Data are expressed as $\mathrm{n}(\%)$, mean \pm standard deviation or as median [interquartile range]. Definition of abbreviations: $\mathrm{N} 1=$ stage $\mathrm{N} 1 ; \mathrm{N} 2=$ stage N2; N3 = stage N3; REM = rapid eye movements; $\mathrm{SpO}_{2}=$ pulsed oxygen saturation; $\mathrm{TST}=$ total sleep time; $\mathrm{PtcCO}_{2}=$ transcutaneous carbon dioxide pressure. ${ }^{*}=p<0.05$ compared to subjects with an AHI $<15$ at polysomnography \# $=\mathrm{p}<0.05$ compared to subjects without sleep hypoventilation. 


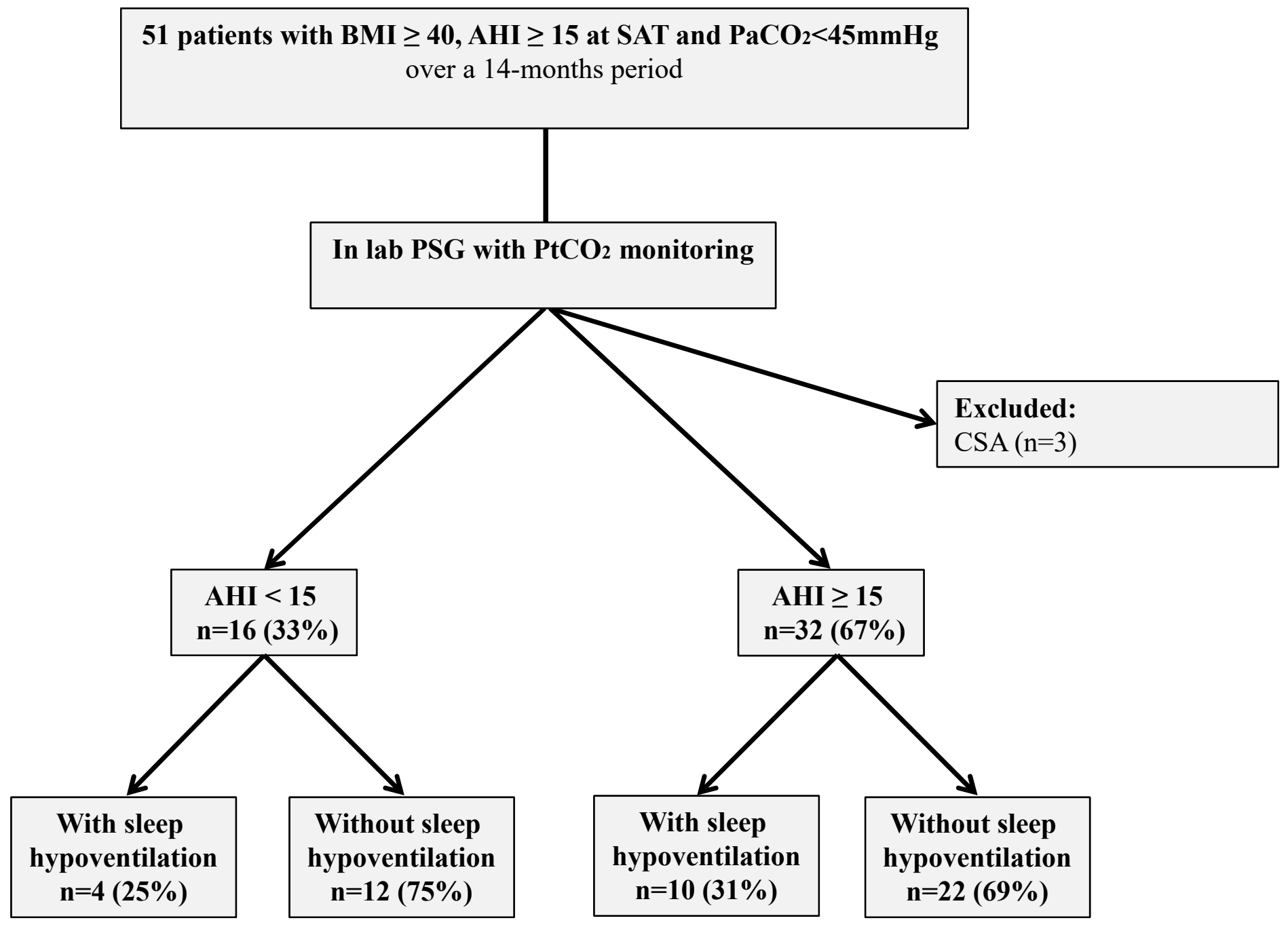


Figure 2

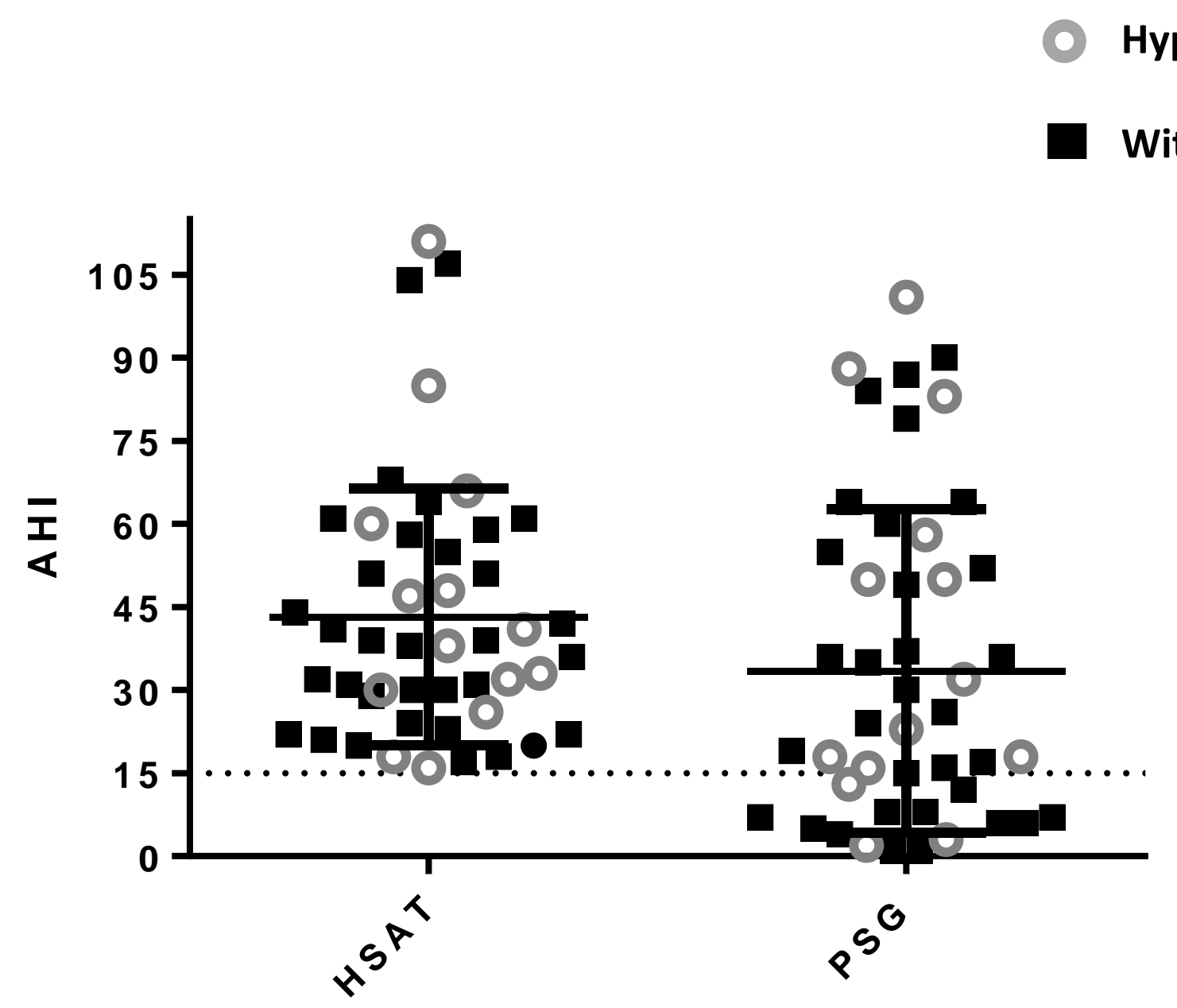

